\title{
UMA ANÁLISE COMPOSICIONAL DA ACIONALIDADE DAS CONSTRUÇÕES COM VERBOS LEVES
}

\author{
A COMPOSITIONAL ANALYSIS \\ ON AKTIONSART FOR LIGHT VERB CONSTRUCTIONS \\ Maurício Resende | Lattes | mauri_cio_resende@hotmail.com
Universidade Estadual de Campinas | CNPq
}

Resumo: Este trabalho examina a acionalidade das construções com verbos leves, analisando as propriedades que fazem que uma mesma situação verbal pertença a classes acionais distintas quando expressa por um verbo pleno ou por uma construção com verbo leve. Assim, assumindo pressupostos da semântica formal e da semântica lexical, o objetivo deste trabalho é examinar os recursos linguísticos que desempenham algum papel na composição aspectual das construções com verbos leves. A partir disso, este trabalho conclui que (i) os verbos leves apresentam uma certa preferência por determinada classe acional que pode influenciar a interpretação semântica do predicado; (ii) o tipo de determinante influencia tanto o tipo de interpretação quanto a constituição acional do predicado; (iii) as construções com verbos leves podem fazer que um determinado predicado mude de classe acional.

Palavras-chave: Acionalidade; Determinantes; Construção com verbos leves.

Abstract: This paper examines the Aktionsart of light verb constructions, by analyzing how the elements constituting them interfere on the Aktionsart of the predicate; moreover, this study analyzes how a verbal situation can belong to different aspectual groups, when they are expressed by full verbs or by light verb constructions. Thus, based on assumptions from Formal Semantics and Lexical Semantics, the main goal of the present work is to investigate the linguistic devices playing some role on the aspectual composition of light verb constructions. Hence, this work concludes that (i) the light verbs present a certain preference for some aspectual groups; (ii) the kind of determiner influences both interpretation and Aktionsart; (iii) the light verb constructions can make a given predicate shift its aspectual properties.

Keywords: Aktionsart; Determiners; Light verb constructions. 


\section{Introdução}

Dentro dos estudos linguísticos, considera-se que as situações verbais são expressas em português por meio de, pelo menos, três recursos linguísticos, a saber, verbos plenos, como em (1a); nominalizações, como em (1b); e construções com verbos leves, como $\mathrm{em}(1 \mathrm{c})$.

(1) (a) A professora conversou com os alunos na semana passada.

(b) A conversa (da professora) com os alunos na semana passada.

(c) A professora teve uma conversa com os alunos na semana passada.

No que tange a estruturas como (1c), alguns trabalhos sobre o português brasileiro (PB), tais como Scher (2003), Davel (2009), Resende (2016a), têm-se debruçado sobre as suas propriedades morfológicas e sintáticas como, por exemplo, estrutura argumental e estrutura do nome deverbal que serve de complemento para o verbo leve. Contudo, o mapeamento das propriedades estritamente semânticas subjacentes a construções com verbos leves, sobretudo no que concerne a diferenças de significado entre, por exemplo, (1a) e (1c), carece ainda de uma análise mais sistemática. Sendo esse o caso, este estudo tem o objetivo de investigar se algumas das propriedades semânticas do predicado, mais especificamente as de acionalidade ${ }^{1}$, sofrem algum tipo de alteração quando uma mesma situação verbal é expressa por um verbo pleno ou, alternativamente, por uma construção com um verbo leve.

A acionalidade das predicações verbais diz respeito à classificação dos eventos, expressos por predicados verbais, de acordo com suas propriedades temporais intrínsecas. Vendler (1967) entende que a acionalidade faz referência ao modo como um predicado verbal esquematiza a noção do tempo e, a partir disso, o autor distribui as predicações verbais em quatro classes acionais (ou aspectuais), a saber, estados, atividades, accomplishments e achievements.

Não há ainda um consenso entre os linguistas a respeito de quais são as propriedades temporais intrínsecas aos predicados verbais que caracterizam cada classe acional e que as distinguem entre si. De todo modo, dado que é necessário fazer uma escolha, este trabalho assume, seguindo Rothstein (2004), que as classes de Vendler (1967) se distinguem através das propriedades [ \pm ESTÁGIOs] e [ \pm TÉLICO], como mostra o Quadro 1. As sentenças em (2) são exemplos desses predicados: estados, atividades, accomplishments e achievements.

\footnotetext{
1 "Acionalidade" está sendo empregado como tradução para o termo alemão Aktionsart e também como sinônimo de "aspecto lexical".
} 


\begin{tabular}{|l|c|c|}
\hline \multicolumn{1}{|c|}{ Classe acional } & Estágios & Telicidade \\
\hline Estados & {$[$-ESTÁGIOs $]$} & {$[$-TÉLICO $]$} \\
\hline Atividades & {$[+$ ESTÁGIOS $]$} & {$[$-TÉLICO $]$} \\
\hline Accomplishments & {$[$ +ESTÁGIOS $]$} & {$[$ +TÉLICO $]$} \\
\hline Achievements & {$[$-ESTÁGIOs $]$} & {$[$ +TÉLICO $]$} \\
\hline
\end{tabular}

Quadro 1. Propriedades intrínsecas às classes acionais

(2) (a) Maria gosta de sua profissão.

(b) A professora conversou com os alunos.

(c) O professor calculou a raiz quadrada de 144 .

(d) O motoqueiro entregou a pizza para o cliente.

Com base nessa classificação, predicações de estado, como em (2a), se definem por terem referência homogênea, [-ESTÁGIOs], ou seja, qualquer parte de gostar de sua profissão é igual a gostar de sua profissão; além disso, predicados estativos não têm um fim inerente, um telos, [-TÉLICO], isto é, não há nada intrínseco a gostar de sua profissão que lhe garanta um fim, um ponto de culminação.

$\mathrm{Em}(2 \mathrm{~b})$, há um predicado de atividade, e esse predicado pressupõe estágios - [+ESTÁGIOs]; por exemplo, uma conversa é feita de, pelo menos, duas pessoas falando. Nesse caso, então, a fala de uma pessoa poderia ser considerada como um estágio da predicação verbal, e a fala da outra pessoa, um estágio distinto. Com relação ao telos, trata-se de uma predicação atélica, pois não há nada inerente a conversar que lhe atribua um fim, ou seja, não há nada estritamente linguístico no predicado conversar com os alunos que garanta uma culminação para essa atividade.

Com (2c), está-se diante de um predicado incremental de accomplishment que pressupõe estágios e para o qual se prevê um ponto de culminação, isto é, calcular a raiz quadrada de 144 pressupõe um telos, qual seja, o de concluir o cálculo. A predicação verbal tem um objetivo, um fim intrínseco. Adicionalmente, cumpre notar que um predicado incremental é aquele em que diferentes estágios caracterizam o predicado, ao passo que, em uma predicação não incremental, os estágios são iguais. A propriedade de ser incremental pode ser ilustrada, por exemplo, na diferença entre calcular a raiz quadrada de 144 - em que os estágios são fazer a racionalização, a multiplicação etc. - e dormir até as $11 \mathrm{~h}$ - cujos estágios são todos homogêneos entre si.

Finalmente, $(2 \mathrm{~d})$ apresenta uma predicação de achievement que não contém estágios, pois trata-se de um evento que se dá em um único momento - um evento instantâ- 
neo, pontual; além disso, é um evento télico, porque pressupõe um fim, no caso de (2d), a entrega. Para esse tipo de predicação, entende-se que o início e o término do evento recaem sobre a mesma instância temporal.

Considerando as dificuldades em determinar com clareza em que classe aspectual incluir um predicado, trabalhos subsequentes aos de Vendler, como Dowty (1979) e Kearns (2000), propuseram uma série de testes que permitem diagnosticar com mais segurança a classe acional do predicado. Nesse sentido, verificar se há variação na acionalidade do predicado - a depender do recurso que o expressa - significa responder da mesma maneira aos testes propostos para a determinação da classe acional. Assim, o Quadro 2 reúne um certo conjunto de testes linguísticos bastante utilizados na literatura para determinar com mais clareza o pertencimento de um dado predicado a uma dada classe acional. Esses testes são mais bem explorados na seção 1 .

\begin{tabular}{|l|c|c|c|c|}
\hline \multicolumn{1}{|c|}{ Teste } & Est & Ativ. & Acc. & Ach. \\
\hline Perífrase progressiva & & $\mathrm{X}$ & $\mathrm{X}$ & $\mathrm{X}$ \\
\hline Imperativo & & $\mathrm{X}$ & $\mathrm{X}$ & $\mathrm{X}$ \\
\hline Verbos do tipo forçar & & $\mathrm{X}$ & $\mathrm{X}$ & $\mathrm{X}$ \\
\hline Advérbios do tipo cuidadosamente & & $\mathrm{X}$ & $\mathrm{X}$ & \\
\hline Adjuntos da forma por $x$ tempo & $\mathrm{X}$ & $\mathrm{X}$ & & \\
\hline Imperfectivo (com acarretamento) & $\mathrm{X}$ & $\mathrm{X}$ & & \\
\hline Auxiliar aspectual parar de (com acarretamento) & & $\mathrm{X}$ & & \\
\hline Auxiliar aspectual terminar de (com culminação) & & & $\mathrm{X}$ & \\
\hline Adjuntos da forma em $x$ tempo (com culminação) & & & $\mathrm{X}$ & $\mathrm{X}$ \\
\hline Adjuntos da forma $a x$ tempo (com culminação) & & & & $\mathrm{X}$ \\
\hline
\end{tabular}

Quadro 2. Conjunto de testes para determinação da classe acional

As construções com verbos leves (CVLs) são um tipo de recurso bastante comum (e produtivo) em algumas línguas para descrever situações verbais. Scher (2003), por exemplo, assume que uma CVL apresenta três propriedades: (i) tem uma sentença correspondente empregando um verbo pleno; (ii) apresenta como complemento nominal um nome de ação (em geral, deverbal) que predica sobre eventos; (iii) contém um verbo principal semanticamente vago, isto é, um verbo tematicamente vazio, marcado para pessoa e tempo - um exemplo desse tipo de construção pode ser encontrado em (1c).

Com relação ao nome que serve de núcleo para as CVLs, ele geralmente consiste de um nome deverbal, ou seja, formado a partir de um verbo. Não há um consenso a respeito de qual é o conjunto de processos morfológicos responsáveis pela formação dos 
nomes deverbais em português. Entretanto, com alguma variação, linguistas e gramáticos concordam que é possível formar nomes a partir de verbos por meio de um sufixo com realização fonológica (lavagem, pensamento, realização), de um sufixo zero (olhar, orientando, gemido) e de uma derivação regressiva - como é tradicionalmente chamada - (fala, ataque, grito). ${ }^{2}$

Não é objetivo deste trabalho discutir a caracterização morfológica subjacente a esses processos; porém, é importante fazer menção aos recursos morfológicos responsáveis por transformar verbos em nomes, porque alguns trabalhos ${ }^{3}$ têm chamado a atenção para o fato de que o dispositivo morfológico empregado na derivação pode disparar diferentes leituras aspectuais no predicado e, consequentemente, interferir nas suas propriedades acionais.

Dessa forma, empregando uma metodologia hipotético-dedutiva, este estudo, com o objetivo de controlar os recursos linguísticos que podem exercer influência sobre a acionalidade do predicado, restringe-se apenas às construções com verbos leves compostas por um nome deverbal formado pela tradicionalmente chamada derivação regressiva ${ }^{4}$ (como em (1c)), ou seja, aqueles nomes que não envolvem a adjunção de um sufixo fonologicamente visível. Ademais, o conjunto de verbos leves analisados, como detalhado a seguir, é formado por dar, fazer e ter.

Resende (2016a) mostrou que a operação morfológica que forma essas nomes não provoca alterações na acionalidade do predicado, já que verbos estativos (tais como desejar e desprezar) formam nomes estativos (desejo e desprezo respectivamente), do mesmo modo que ocorre com nomes de atividade (abraçar/abraço, brigar/briga), de accomplishments (analisar/análise, cortar/corte), de achievement (entregar/entrega, escolher/escolha), que pertencem à mesma classe acional dos verbos dos quais derivam.

Além disso, com relação à segunda propriedade assumida por Scher (2003), esta análise propõe um alargamento dessa condição à configuração de uma CVL e postula que esse tipo de construção não está restrita a nomes de ação, mas que ela se aplica a qualquer nome deverbal que apresente uma interpretação verbal, ou seja, a disponibilidade de uma CVL para expressar um predicado verbal não está restrita à interpretação da ação denotada pelo nome, já que as construções como ter desejo e ter interesse, por exemplo, contêm nomes deverbais (desejo e interesse) que não denotam ação; mas, sim, estados.

Quanto a (iii), Scher postula que, para o português, o conjunto de verbos leves é constituído por dar, fazer, levar, tomar, pôr e ter; porém, no caso dos verbos que ocorrem

${ }^{2}$ Cf. Resende (2016b) para uma discussão desses casos e referências.

${ }^{3}$ Cf. Brinton (1995), Lemle (2002), Resende (2016a), entre outros.

${ }^{4}$ Embora seja preciso deixar claro que, ao fazer referência ao processo tratado pela tradição como derivação regressiva, este estudo não se está comprometendo com a caracterização morfológica atribuída a ele. 
com os nomes deverbais em questão, o conjunto é composto por dar, fazer, levar, ter e tomar. Além disso, no que toca à configuração dessas construções, os sintagmas complemento de uma CVL contendo nomes deverbais podem aparecer em diferentes formas morfossintáticas, tais como singular/plural - dar um beijo, dar uns pegas; determinante definido/indefinido - fazer a venda, fazer uma entrega; singular nu/plural nu - ter respeito, dar desculpas.

Outra característica das CVLs é a de que o nome que lhe serve de complemento nem sempre consiste de um nome deverbal (como já observado por Scher) ainda que sua forma coincida com a de uma nominalização; ${ }^{5}$ exemplos desse caso são aviso em dar um aviso (= avisar) e desenho em fazer um desenho (= desenhar) - estes são instâncias de nomes morfologicamente básicos, que originam verbos denominais (avisar e desenhar respectivamente).

Do mesmo modo, existem nomes deverbais que aparecem em CVLs, mas que não constituem paráfrases de uma situação expressa por um verbo pleno - conforme a propriedade (i) - o que se observa em volta em dar uma volta ( $\neq$ voltar), conta em dar conta ( $\neq$ contar) e em tomar conta ( $\neq$ contar), trabalho em dar trabalho ( $\neq$ trabalhar), limpa em fazer uma limpa ( $\neq$ limpar) etc.

Assim sendo, uma vez que o objetivo deste trabalho é verificar se há variação ou não na acionalidade do verbo pleno com relação à CVL que lhe serve como paráfrase, convém desconsiderar todas as CVLs que não contêm nomes deverbais e todas as CVLs que contêm nominalizações, mas que não constituem paráfrase de uma predicação verbal expressa por um verbo pleno. ${ }^{6}$

\section{A acionalidade das construções com verbos leves}

Nesta seção, são firmadas algumas considerações a respeito da morfossintaxe das construções válidas para tal análise, a saber, as CVLs (i) empregam os verbos dar, fazer e ter; (ii) utilizam nomes deverbais formados pela então chamada derivação regressiva; (iii) constituem paráfrase de uma estrutura que emprega um verbo pleno.

Cercadas as CVLs de interesse deste estudo, convém explicitar que a decisão sobre em que classe acional incluir um dado predicado se pauta na maneira como eles respondem aos testes selecionados para o diagnóstico de sua acionalidade - como aqueles que aparecem no Quadro 2. Mais que isso, considerar que as CVLs "mantêm a acionalidade”

\footnotetext{
5 Termo tradicionalmente empregado para fazer referência ao processo ou ao resultado de transformação de um verbo em um nome.

${ }^{6}$ E igualmente aquelas CVLs que consistem de expressões idiomáticas ou cristalizadas (tais como dar um chega p'ra lá).
} 
do predicado-base significa que elas dão o mesmo tipo de resposta a, pelo menos, dois testes elencados.

Para a testagem das propriedades acionais das construções com verbos leves, parte-se de Resende (2016a, 2016c), para quem os nomes deverbais - de interesse deste estudo - preservam a acionalidade dos verbos dos quais derivam. Portanto, ao considerar, por exemplo, um predicado de atividade como beijar, consequentemente se dispõe de um nome deverbal de atividade como beijo, e o objetivo é verificar se a CVL correspondente dar um beijo pertence igualmente à classe das atividades.

Partindo disso, considera-se (3) - um conjunto de construções com verbos leves cujos nomes são derivados de verbos nocionalmente estativos.

(3) ter descanso, ter desejo, ter desprezo, ter dúvida, ter gosto, ter interesse, ter melhora, ter respeito.

A partir dos dados em (3), a primeira observação é a de que não há CVLs empregando nem o verbo fazer nem o verbo dar. Isso pode ser devido ao fato de que os predicados de estado, como defendem muitos semanticistas, não denotam intenção ou volição, e os verbos fazer e dar carregam em seu significado um traço, em alguma medida, volicional. A respeito de fazer, Basílio (2007) observa que as expressões "fazer + nome" significam basicamente "executar um ato", o que pode explicar, também, a rara ocorrência (e nesse conjunto de dados, nula) desse verbo com predicações de estado.

Primeiramente, com relação aos predicados estativos, Dowty (1979) entende que predicações estativas não se combinam bem com perífrase progressiva, como mostram as sentenças em (4).

(4) (a)*Aquela criança está tendo desejo de ir para Disney.

(b) *Ana está tendo desprezo por Marcos.

Em (4), vê-se que, como proposto por Dowty, as CVLs compostas por nomes estativos rejeitam perífrase progressiva. Além disso, Dowty (1979) mostra que predicados de estado não são compatíveis com advérbios do tipo de cuidadosamente. A respeito disso, observe-se (5).

(5) (a) *Aquela criança teve cuidadosamente desejo de ir para Disney.

(b) *Ana teve desprezo por Marcos / cuidadosamente.

Assim, partindo de (4) e (5), é possível concluir que CVLs contendo nomes estativos são igualmente predicados de estado. Pondo de lado esses casos, no que concerne a 
CVLs que alocam nomes deverbais de atividade, Brinton (1995) mostra que, em inglês, existem diferenças de acionalidade entre um verbo pleno de atividade e uma CVL que emprega um nome deverbal de atividade. Para a autora, a CVL divide arbitrariamente o predicado em porções de curtos espaços de tempo; por exemplo, em breathe ('respirar') há uma atividade (atélica e homogênea), mas em take a breath ('tomar fôlego'), há uma porção delimitada da atividade de respirar, uma delimitação entendida como um telos, em última análise, transformando uma predicação de atividade em um predicado de accomplishment.

Adicionalmente, a autora observa, sobre esse tipo de construção em inglês, que give ('dar') e take ('levar/tomar') são os verbos leves que geralmente aparecem com predicados de atividades. Quanto ao português, consideram-se os dados em (6) de CVLs que empregam nomes deverbais de atividade.

(6) dar um abraço, ter acesso, dar ajuda, dar apoio, dar auxílio, dar conforto, dar consolo, dar um beijo, dar um berro, ter uma briga, dar um chute, ter uma conversa, fazer esforço, dar incentivo, dar um grito, dar um mergulho, dar um passeio, dar um pulo, dar um salto, ter um sonho, dar uma surra, fazer uso, fazer uma visita, dar um xingo.

A partir dos dados em (6), observa-se que CVLs com nomes de atividade não oferecem restrições quanto ao tipo de verbo leve empregado: há tanto exemplos com o verbo $d a r^{7}$ e fazer ${ }^{8}$ quanto com o verbo ter ${ }^{9}$, embora em menor número. Como mencionado, Basílio (2007) observa que construções com o verbo fazer denotam "executar um ato". Para a autora, existe inclusive uma série de atos, expressos por uma construção "fazer + nome”, bastante discerníveis entre si. Em síntese, para a autora, construções com o verbo fazer denotam "atos contínuos" (como fazer massagem, fazer carícias, fazer exercícios).

No que concerne ao aspecto lexical, Dowty (1979) observa que, em predicados de atividade, existe uma relação de acarretamento semântico de (a) para (b) quando há emprego do aspecto imperfectivo para o perfectivo, como exemplificam as sentenças em (7) e (8), contendo CVLs com nomes de atividade empregando o verbo fazer.

(7) (a) O diretor fazia uso do computador.

(b) O diretor fez uso do computador.

\footnotetext{
7 Cf. Scher (2003, 2006), Basílio (2007), Davel (2009), Medeiros (2010), entre outros, para o emprego do verbo leve dar em construções com complementos de outra natureza.

${ }^{8}$ Cf. Basílio (2007), entre outros, para demais construções empregando o verbo fazer.

9 Cf. Viotti (2003) para outros tipos de construção com o verbo ter.
} 
(8) (a) A neta fazia uma visita para a avó.

(b) A neta fez uma visita para a avó.

Nas sentenças em (7), o uso do imperfectivo em (a) acarreta (b). Se é verdade que o diretor fazia uso do computador, é igualmente verdadeiro que ele fez uso do computador. $\mathrm{O}$ mesmo aplica-se à visita da neta em (8), pois se a neta fazia uma visita, é verdade que a neta fez uma visita.

No que tange a CVLs que empregam o verbo dar, Basílio (2007) classifica as expressões "dar + nome" segundo o seu uso; mais especificamente, a autora defende que, em geral, existe uma oposição sistemática entre construções "dar + nome" e "fazer + nome"; estas, para atos contínuos e emissões de voz, e aquelas, para atos momentâneos e atos de fala. Convém observar, contudo, que essa distinção pouco tem a dizer sobre as propriedades estritamente linguísticas dessas CVLs; de todo modo, cumpre tecer alguns comentários sobre a afirmação de que construções "dar + nome” geralmente indicam atos momentâneos.

Interpretando Basílio (2007), é possível afirmar que a leitura de "ato momentâneo" atribuída a expressões com o verbo dar (dar um chute, dar um pulo) e a leitura de Brinton (1995) para o inglês convergem no seguinte sentido: entende-se que uma CVL com um nome deverbal de atividade consiste de uma operação de extração de unidade em que, por exemplo, um único subevento de pular (dar um pulo) consiste de um ato momentâneo, de uma porção delimitada de um predicado de atividade.

Nesse sentido, "atos momentâneos" e "extração de unidade" estão fazendo referência a subeventos de um evento maior da mesma natureza. Esse é o caso dos predicados semelfactivos, em que há uma série de eventos pontuais (télicos) que podem compor um evento atélico maior, tais como chutar, saltar, pular, socar etc. ${ }^{10}$ Assim, esta análise defende que chutar é uma predicação atélica composta por estágios, subeventos (pontuais) de chutar.

A operação de extração de unidade a que Brinton (1995) refere-se se dá quando um predicado semelfactivo de atividade é expresso por uma CVL, no caso do inglês, com give ('dar') e take ('levar/tomar'). Em português, ela só ocorre com o verbo dar; nessa operação, ocorre uma "extração da unidade" em que um subevento da predicação torna-se um “ato momentâneo", como é visto em (9).

${ }_{10}$ Para Kearns (2000), essa característica torna difícil sua classificação, tanto que há autores que os incluem na classe dos achievements. 
(9) (a) Maria deu um chute na bola.

(b) João deu um pulo na piscina.

No entanto, chutar (verbo de atividade) e dar um chute (bem como os outros predicados semelfactivos) não respondem da mesma maneira que os outros predicados de atividade aos testes de que normalmente se dispõe para determinar a classe acional do predicado. Dowty (1979), por exemplo, mostra que predicados de atividade apresentam acarretamento semântico de (a) para (b) quando ocorrem com o adjunto por $x$ tempo, como se observa em (10).

(10) (a) * Maria deu um chute na bola por cinco segundos.

(b) *João deu um pulo na piscina por cinco segundos.

As sentenças em (10) não são possíveis, o que mostra que a CVL que emprega o verbo leve dar com esse tipo de predicação (semelfactiva) causa mudanças no aspecto lexical, transformando uma predicação de atividade em um predicado de achievement; porém, com outros verbos de atividade, ainda que sejam empregados com o verbo dar e um determinante, não há mudança na acionalidade, o que é constatado em (11).

(11) (a) O pai deu uma surra no filho por dez minutos.

(b) A mãe deu um passeio por meia hora.

O mesmo se aplica a (12) e (13).

(12) (a) A professora teve uma conversa com o aluno por duas horas.

(b) A professora teve uma conversa com o aluno.

(13) (a) $\mathrm{O}$ vereador teve acesso às contas da prefeitura por dois mandatos.

(b) $\mathrm{O}$ vereador teve acesso às contas da prefeitura.

Assim, no que diz respeito a CVLs que empregam nomes de atividade, há tanto casos de mudança de acionalidade quanto casos de preservação. Adicionalmente, Brinton (1995) afirma que, em inglês, situações verbais expressas por CVLs não descrevem predicados accomplishment, porque, segundo a autora, esse tipo de construção não se combina bem com predicados que denotam limitação temporal e espacial ou atingimento de objetivos. Sendo esse o caso, as CVLs do inglês se comportam diferentemente das do português, pois tais combinações são perfeitas nessa língua, como indica (14).

(14) fazer uma análise, fazer um anúncio, fazer uma busca, fazer um cálculo, fazer um corte, fazer uma crítica, fazer uma denúncia, fazer uma pergunta, fazer uma pesquisa, fazer um relato. 
A partir dos dados em (14), constata-se que as CVLs que empregam nomes de accomplishment só são produtivas com o verbo fazer. Isso pode ser resultado do traço de volição/intenção presente no verbo leve que faz que ele se combine bem com predicações télicas, isto é, volição ou intenção em atingir um telos. Brinton (1995) entende que a impossibilidade de uma CVL empregando o verbo ter com accomplishments é justamente a sua incompatibilidade com predicados que denotam ações definidas ou delimitação espacial/temporal (o que, por outro lado, motiva sua ocorrência em predicados de atividade e estado).

Para Dowty (1979), em predicações accomplishment que ocorrem com o auxiliar aspectual parar de, não há acarretamento semântico de (a) para (b). Observa-se, então, (15).

(15) (a) A menina parou de fazer a denúncia do roubo.

(b) A menina fez a denúncia do roubo.

Em (15), não há acarretamento semântico de (a) para (b), pois a interrupção da denúncia não acarreta na culminação do evento. Adicionalmente, muitos semanticistas entendem que os predicados de accomplishment são os únicos que se combinam bem com o auxiliar aspectual terminar de. Acerca disso, considere-se (16).

(16) (a) A menina terminou de fazer a denúncia do roubo.

(b) O aluno terminou de fazer o cálculo da raiz quadrada de 144.

Ao observar (16), constata-se a gramaticalidade das sentenças com o auxiliar aspectual terminar de e, portanto, é possível concluir que CVLs que empregam nomes deverbais de accomplishment também descrevem sentenças accomplishment.

No que diz respeito a achievements, Brinton (1995) mostrou que em inglês nomes deverbais de achievement não são produtivos em CVLs; segundo a autora, os únicos exemplos são make an escape ('dar uma fugida') e make a get-away ('fazer uma fuga'). Para Brinton, isso se deve também ao fato de as CVLs em inglês não figurarem com predicações que denotam delimitação de tempo ou de espaço. Assim como para accomplishments, isso não é algo que se verifica em português. Ainda que não sejam muito numerosas, CVLs com nomes de achievement são produtivas, como aponta (17).

(17) fazer uma compra, fazer uma entrega, fazer uma escolha, fazer um passe, fazer uma troca, fazer uma venda.

Ao observar os dados em (17), é possível perceber que as predicações com nomes de achievement só se combinam com o verbo fazer. Novamente isso pode ser explicado 
pelo traço volicional/intencional presente no verbo. Mais que isso, Dowty (1979) entende que predicados achievement são incompatíveis com o auxiliar aspectual terminar de. Por outro lado, apresentam compatibilidade com o adjunto $a x$ tempo. Sentenças que empregam CVLs com achievement aparecem em (18) e (19).

(18) (a) Marcos terminou de fazer a compra do boi.

(b) O motoqueiro terminou de fazer a entrega da pizza.

(19) (a) Nei fez a compra do boi às 9 h30min.

(b) O motoqueiro fez a entrega da pizza às $22 \mathrm{~h} 30 \mathrm{~min}$.

Nas sentenças anteriores, é possível perceber que as CVLs que contêm o verbo $f a-$ zer são compatíveis com o auxiliar aspectual terminar de, o que é um indício de que essas CVLs descrevem sentenças accomplishment. Quanto à sua boa formação com adjuntos da forma $a x$ tempo, este indica a instância temporal de algum ponto do evento, do início ou da culminação; logo, elas não se comportam como predicados de achievement.

Então, no caso de CVLs "fazer + nome" de achievement, o verbo fazer transforma um ato instantâneo em um processo, fazendo com que o evento pontual da compra seja estendido, e a predicação verbal passe a denotar todo o processo de comprar (escolha, pagamento etc.), atribuindo a fazer uma venda as mesmas propriedades acionais de fazer um cálculo, por exemplo, transformando, em última análise, um predicado que contém um nome de achievement em uma predicação de accomplishment.

Em síntese, o Quadro 3 apresenta um resumo das transformações que ocorrem na acionalidade de um predicado quando expresso por um nome e por uma construção com verbo leve que o aloca.

\begin{tabular}{|l|l|}
\hline \multicolumn{1}{|c|}{ Nome deverbal } & \multicolumn{1}{c|}{ CVL } \\
\hline Estados & Estados \\
\hline Atividades & Atividades \\
\hline Atividades semelfactivas & Achievements \\
\hline Accomplishments & Accomplishments \\
\hline Achievements & Accomplishments \\
\hline
\end{tabular}

Quadro 3. Classificação dos predicados a partir de suas formas

Pondo de lado esses casos, cumpre tecer algumas considerações adicionais a respeito do papel que o verbo leve tem na caracterização do predicado e, mais especificamente, na sua (in)compatibilidade com determinada classe acional. Cumpre lembrar que o conjunto de verbos leves analisados é dar, fazer e ter. 
Com relação ao verbo dar, como foi visto, ele não impõe restrições quanto à presença de determinante, já que é possível tanto dar uma surra quanto dar conforto. Outra característica desse verbo leve é a de que ele só ocorre com predicações que descrevem atividades. Isso se deve tanto à sua preferência por predicações atélicas quanto ao traço de agentividade, volição, intenção, que dar traz de sua raiz e que não é compatível (como foi mostrado) com a classe aspectual dos estados.

Quanto à ocorrência exclusiva com predicados de atividade, ela pode ser explicada pela morfossintaxe dessas construções. Medeiros (2010), para construções com o verbo dar em sentenças como Rita deu consolo para a amiga, postula que há um argumento externo que é o agente que causa o evento, o qual é expresso pelo argumento interno do verbo, e um PP que diz respeito ao lugar onde o evento se deu.

Nessa análise, Rita é o agente do evento dar consolo e a amiga é o elemento afetado pelo evento, ou seja, aquele que recebe o consolo/é consolado. Nota-se que há uma sistematização que subjaz a esse tipo de CVL, como se vê em dar um(a) soco/chute/surra/xingo e em dar apoio/conforto/consolo em que o argumento externo é agente, o nome deverbal é o evento e o sintagma preposicionado é o objeto afetado pelo evento.

No que tange a CVLs que empregam o verbo fazer, viu-se que elas não ocorrem com nomes estativos, porque, como já discutido, a classe acional de estado não é compatível com agentividade. Por outro lado, fazer é o único verbo leve que aparece com CVLs que contêm nomes deverbais de predicados télicos (accomplishments e achievements). Essa compatibilidade pode ser resultado da volição/intenção em executar um determinado evento. Além disso, há alguns poucos casos com "fazer + nome de atividade" (sem que ocorra mudança na classe acional), tais como fazer uso/esforço/uma visita, mas é possível notar que há igualmente uma noção de agentividade envolvida, já que essas predicações requerem intenção e volição.

Finalmente, com o verbo ter só aparecem nomes derivados de verbos estativos e de atividade. Brinton (1995) explica que isso se dá porque ter não é compatível com situações verbais que denotam algum tipo de limitação, temporal ou espacial, ou seja, télicas; por outro lado, combinam-se bem com predicados atélicos. Adicionalmente, Viotti (2003) afirma que construções com o verbo ter não provocam mudança na classe acional do predicado; o que também é, de fato, verificado, pois nas CVLs em que ele aparece (diferentemente de alguns casos com dar e alguns com fazer), não há mudança na classe aspectual. 


\section{0 papel do determinante na acionalidade de uma CVL}

Anteriormente, tratou-se do papel que o nome deverbal e também o verbo leve podem exercer sobre o aspecto lexical de um predicado quando expresso por uma CVL. A esta seção, portanto, cabe discorrer sobre o papel que o determinante (ou a ausência dele) pode exercer na constituição da acionalidade do predicado. Isso porque os dados apresentados anteriormente mostram uma certa sistematicidade quanto ao seu emprego, a saber, CVLs sem determinante não sofrem variação no seu aspecto lexical, como é o caso dos estados (ter desejo) e das atividades não semelfactivas (dar apoio); CVLs que mudam de classe acional são aquelas em que há determinante, tais como as de predicados semelfactivos de atividade que se transformam em predicados de achievement (dar um chute) e as com nomes deverbais de achievement que se tornam predicações accomplishment (fazer uma troca).

Na verdade, também foi mostrado que existem algumas CVLs que têm determinante e que não sofrem alterações na acionalidade, como é o caso das CVLs de atividades e das de accomplishment, e é objetivo desta seção mostrar em que consiste essa diferença e a quais propriedades subjazem essa sistematização.

Nas CVLs analisadas na seção anterior, viu-se que a maioria delas era composta por um determinante singular, quer definido $(o / a)$ quer indefinido (um/uma). A respeito do determinante singular em CVLs, Davel (2009) defende que um/uma realiza uma operação de extração de um elemento singular (e indeterminado) de um certo conjunto; entretanto, essa hipótese de Davel é insuficiente para explicar o que, de fato, acontece com os nomes deverbais nas CVLs.

É verdade que, no caso de predicados semelfactivos como chutar, um em dar um chute pode ser entendido como um recurso de extração de um elemento de um certo conjunto (chutar); todavia, ancorado nessa definição, já não é muito claro o que ocorre, por exemplo, em um encontro, uma visita ou uma conversa; nesses casos, não é óbvio qual é, de fato, o elemento que está sendo extraído e nem qual é o conjunto de que se está extraindo esse elemento.

Quanto à acionalidade das CVLs, foi possível perceber que determinantes são compatíveis com predicados télicos, por exemplo, no caso de CVLs de achievement (dar um chute/soco/pulo/salto) e de CVLs de accomplishment (fazer uma análise/pesquisa/venda/ entrega/troca), isso porque um/uma reforça a ideia de delimitação que, por definição, é compatível com telicidade. Por outro lado, isso explica porque nomes deverbais atélicos geralmente não se combinam com determinantes, como é o caso dos estativos (ter des- 
prezo/respeito/desejo) e dos de atividade (ter acesso, fazer uso/esforço, dar consolo/apoio/ conforto).

É verdade que, como foi visto, existem nomes de atividade - não semelfactivas que aparecem com determinante (ter uma briga/conversa, fazer uma visita, dar uma sur$r a)$; embora não haja um telos, é possível, por meio do emprego de um/uma, cindir arbitrariamente o evento de tal modo que a linha de corte coincida com a culminação de uma porção do evento atélico, e que essa cisão seja interpretada como um tipo de delimitação, na prática, espacial ou temporal etc. (dependendo do predicado).

Brinton (1995) entende que, nesses casos, há uma interpretação de "fazer determinada atividade por um certo tempo". Para a autora, construções desse tipo com o verbo ter disparam a leitura de "delimitação arbitrária de uma atividade". No entanto, para o português, isso se dá também com os verbos dar e fazer, uma vez que fazer uma visita, dar uma surra assim como ter uma briga, denotam "fazer a atividade por algum tempo". Nesses casos, a delimitação não tem a ver com a telicidade (uma limitação interna ao predicado), mas sim com algum tipo de limite extralinguístico, como se vê em (20).

(20) (a) Ana teve duas conversas com o namorado hoje: uma de manhã, outra à tarde.

(b) Ele deu dois passeios hoje: um na praia e outro no parque.

Como visto em (20), as delimitações provocadas pelo determinante são extralinguísticas: temporal em (a) e espacial em (b); por isso, não há mudança na classe acional, já que mudar a acionalidade significa, no limite, alterar propriedades internas ao predicado.

Quanto à ideia de indeterminação presente em um/uma, Davel (2009) defende que isso é consequência da incapacidade de se determinar sobre qual referente - dentro de um número finito ou infinito - se está falando. Além disso, Lyons (1999) argumenta que a escolha por um determinante (em detrimento de outro) se deve, em alguns casos, à propriedade de identificabilidade.

Para o autor, a identificabilidade diz respeito à possibilidade de se identificar o referente determinado (pelo determinante); essa propriedade é geralmente expressa por $o / a$. Além disso, para Davel (2009), o/ a possibilita delimitar o objeto da referência. Assim, a diferença entre um/uma e $o / a$ respeita à identificabilidade do referente, o que é visto em (21).

(21) (a) O professor fez um cálculo.

(b) *O professor fez um cálculo da raiz quadrada de 144. 
(c) O professor fez o cálculo.

(d) O professor fez o cálculo da raiz quadrada de 144.

Como aparece em (21), a identificabilidade do referente deu-se por meio de uma locução adjetiva, a qual restringe o cálculo de modo que fosse possível determiná-lo. Na verdade, a identificabilidade, como propõe Lyons (1999), é condição para o emprego de o/ a nesses casos; portanto, deve haver um modo de restringir o nome para que seja possível empregar o determinante definido. Essa restrição pode ser feita contextualmente (por meio de enriquecimento pragmático ou de um fundo conversacional compartilhado) ou de um expediente sintático - como em (21d), por exemplo). ${ }^{11}$ Porém, uma vez feita a restrição, o predicado torna-se incompatível com determinante indefinido - como atesta a agramaticalidade de (21b).

No tocante à acionalidade, Bertucci (2011) entende que o emprego de $o / a$ só se dá com predicados télicos, pois o artigo definido mede o evento do qual ele participa. Naturalmente, no caso de accomplishments e achievements (predicações télicas), talvez a substituição de um/uma por $o$ / a seja em termos de identificabilidade do referente - o que se vê na diferença entre (21a) e (21c). Contudo, vale checar se isso ocorre também para as atividades; para tanto, considera-se (22).

(22) (a) Ana teve a conversa mais difícil de sua vida hoje de manhã.

(b) Os pais fizeram a visita tão esperada para a filha.

Não é objetivo deste estudo discutir os recursos linguísticos subjacentes à definitude; ${ }^{12}$ entretanto, cabe verificar se essa propriedade provoca mudança de classe acional. Para isso, testam-se a compatibilidade com terminar de em (23) e a relação de acarretamento empregando por $x$ tempo em (24).

(23) (a) Ana terminou de ter a conversa mais difícil de sua vida.

(b) Os pais terminaram de fazer a visita tão esperada para a filha.

(24) (a) Ana teve a conversa mais difícil de sua vida por uma hora.

(b) Os pais fizeram a visita tão esperada para a filha por uma hora.

As sentenças em (23) mostram-se compatíveis com terminar de e, por outro lado, as sentenças em (24) não acarretam as sentenças em (22), isto é, Ana ter tido a conversa mais difícil de sua vida por uma hora não acarreta que Ana teve a conversa mais difícil de sua vida. Assim, observa-se que as predicações em (22) se tornaram sentenças de accom-

\footnotetext{
${ }^{11}$ Em alguns casos também, com alteração na prosódia como em Pedro deu a surra no irmão.

12 Cf. Lyons (1999) para uma discussão desse fenômeno.
} 
plishment. Portanto, conclui-se que, no caso das atividades, o emprego do determinante definido causa variação na acionalidade.

Ademais, no que concerne ao emprego do determinante plural, a primeira característica de CVLs com determinante plural é a de que elas não são compatíveis com predicações que não aceitam determinantes no singular, tais como estativas em (25a) e algumas de atividade, como em (25b).

(25) (a) *Ana tem respeitos pelos seus professores.

(b) * Maria deu apoios para a amiga terminar o casamento.

A respeito da pluralização, Bertucci (2011) defende que, dependendo do tipo de objeto que compõe o predicado verbal, ocorre uma variação no aspecto lexical. Para o autor, o uso do plural provoca a transformação de achievements em accomplishments. Visando verificar se isso ocorre com CVLs, considere-se (26). Vale lembrar que as únicas CVLs de achievement bem formadas são aquelas derivadas de predicados semelfactivos.

(26) (a) Neymar deu o chute que todos estavam esperando às $14 \mathrm{~h}$.

(b) *Neymar deu os chutes que todos estavam esperando às $14 \mathrm{~h}$.

(c) Neymar terminou de dar os chutes que todos estavam esperando.

A partir de (26), conclui-se que uma CVL achievement se comporta igualmente como achievement. Quando submetido à pluralização, deixa de ser um achievement e passa a ser um accomplishment. A incompatibilidade com ax tempo em (26b) e a compatibilidade com terminar de revelam que dar os chutes é um predicado de accomplishment.

Com relação ao plural para determinantes indefinidos, vejam-se (27) e (28), em que (27a) é uma CVL achievement.

(27) (a) O nadador deu um pulo na piscina às $10 \mathrm{~h}$.

(b) ${ }^{*} \mathrm{O}$ nadador deu uns pulos na piscina às $10 \mathrm{~h}$.

(28) (a) O nadador deu uns pulos na piscina por vinte minutos.

(b) O nadador deu uns pulos na piscina.

Nas sentenças anteriores, a incompatibilidade com o adjunto às $10 \mathrm{~h}$ revela que (27b) não é mais um predicado de achievement - como é em (27a). Da mesma maneira, a compatibilidade com por $x$ tempo com acarretamento semântico de (28a) para (27b) mostra que o predicado sofreu alteração, mas nesse caso com uma variação a mais, que é a da telicidade, ou seja, a pluralização em dar uns chutes torna-o (novamente) um predicado de atividade semelfactivo. 
No caso das CVLs de accomplishment, a pluralização não desencadeia variação na acionalidade, o que pode ser visto pela compatibilidade com terminar de em (29).

(29) (a) O contador terminou de fazer os cálculos.

(b) O contador terminou de fazer uns cálculos.

Além disso, assim como o que ocorre para determinantes no singular, a diferença entre uns/umas e os/as em CVLs de accomplishment diz respeito somente à identificabilidade do referente. Finalmente, para as predicações de atividade que aceitam determinante, anteriormente foi mostrado que, quando empregam um/uma, elas continuam pertencendo à mesma classe aspectual; porém, quando aparecem com $o / a$, elas se tornam predicados de accomplishment. Entretanto, no que tange à pluralização, não há comportamentos distintos: as CVLs de atividade não sofrem mudança da acionalidade, como atesta (30).

(30) (a) Rita parou de ter os sonhos mais estranhos da vida dela.

(b) Rita teve os sonhos mais estranhos da vida dela.

(c) Rita parou de ter uns sonhos estranhos.

(d) Rita teve uns sonhos estranhos.

Como é possível observar nas sentenças anteriores, a compatibilidade com por $x$ tempo e parar de com acarretamento semântico constitui evidência para a afirmação de que não houve mudança na classe acional em virtude da pluralização. Nessas situações, cada evento (indelimitado) atélico se torna um subevento de um evento atélico maior. Além disso, quanto à distinção entre definidos e indefinidos, nesses casos, ela se dá pela identificabilidade da referência.

Por fim, a respeito das CVLs sem determinante, anteriormente, mostrou-se que CVLs que rejeitam determinante singular igualmente não se combinam com determinante no plural. Tal restrição à quantificação faz que esses predicados apareçam no singular sem determinante, mas não no plural sem determinante, o que se observa em (31).

(31) (a) *Maria tem gostos por trabalhos difíceis.

(b) ${ }^{*} \mathrm{O}$ assistente social deu apoios aos desabrigados.

Entretanto, CVLs que podem ter seus nomes quantificados, as quais normalmente aparecem com determinante, podem aparecer sem ele, estejam no singular ou no plural. A respeito disso, Wachowicz \& Foltran (2006) afirmam que sentenças com singular ou plural nu ganham leitura genérica. Bertucci (2011) mostra que o emprego de nominais 
nus desencadeia a mudança de predicados achievement em atividade. Na verdade, a ausência de determinante (para os nomes que aceitam determinante) provoca a transformação de qualquer predicado télico em uma predicação de atividade, como se vê em (32a), com CVLs accomplishment e em (32b) com predicações de achievement.

(32) (a) A função daquele motoqueiro é fazer entrega/entregas.

(b) $\mathrm{O}$ treino daquele atleta é basicamente dar salto/saltos do trampolim.

Nesses exemplos, assim como no caso do uso do determinante plural, cada evento pontual de fazer uma entrega torna-se um subevento de um predicado maior de fazer entrega(s), assim como cada evento pontual de saltar do trampolim constitui subeventos de eventos atélicos maiores de dar salto $(s)$; todavia, a ausência de determinante acarreta ausência de telicidade.

Sendo assim, no que toca a CVLs de atividade propriamente ditas, não ocorrem mudanças no aspecto lexical, como atestam as sentenças em (33).

(33) (a) Criança marrenta tem briga/brigas na escola toda semana.

(b) O que o João fez foi dar beijo/beijos na Maria.

Em síntese, o Quadro 4 reúne os resultados do comportamento do determinante das CVLs no que toca à variação na classe acional.

\begin{tabular}{|l|c|c|c|c|}
\hline Determinante & Estados & Atividades & Accomplishments & Achievements \\
\hline um/uma & não ocorre & $\begin{array}{c}\text { não provoca } \\
\text { alteração }\end{array}$ & $\begin{array}{c}\text { não provoca alte- } \\
\text { ração }\end{array}$ & $\begin{array}{c}\text { não provoca } \\
\text { alteração }\end{array}$ \\
\hline o/a & não ocorre & $\begin{array}{c}\text { transforma } \\
\text { em } \text { accom- } \\
\text { plishment }\end{array}$ & $\begin{array}{c}\text { não provoca alte- } \\
\text { ração }\end{array}$ & $\begin{array}{c}\text { transforma em } \\
\text { accomplishment }\end{array}$ \\
\hline uns/umas & não ocorre & $\begin{array}{c}\text { não provoca } \\
\text { alteração }\end{array}$ & $\begin{array}{c}\text { não provoca alte- } \\
\text { ração }\end{array}$ & $\begin{array}{c}\text { transforma em } \\
\text { atividade }\end{array}$ \\
\hline os/as & não ocorre & $\begin{array}{c}\text { não provoca } \\
\text { alteração }\end{array}$ & $\begin{array}{c}\text { não provoca alte- } \\
\text { ração }\end{array}$ & $\begin{array}{c}\text { transforma em } \\
\text { accomplishment }\end{array}$ \\
\hline$\varnothing$ & $\begin{array}{c}\text { não provo- } \\
\text { ca altera- } \\
\text { ção }\end{array}$ & $\begin{array}{c}\text { não provoca } \\
\text { alteração }\end{array}$ & $\begin{array}{c}\text { transforma em } \\
\text { atividade }\end{array}$ & $\begin{array}{c}\text { transforma em } \\
\text { atividade }\end{array}$ \\
\hline
\end{tabular}

Quadro 4. Influência do tipo de determinante sobre a classe acional

\section{Considerações finais}

Este trabalho analisou a acionalidade das construções com verbos leves formadas pelos verbos dar, fazer e ter e por nomes deverbais formados pela então chamada deriva- 
ção regressiva, empregando ou não determinantes ou o morfema de plural. O objetivo central do trabalho foi determinar quais são os recursos linguísticos responsáveis pelo caráter aspectual composicional das CVLs e, a partir dele, foi mostrado que o aspecto lexical das predicações verbais expressas por CVLs é composicional, já que pode depender tanto da classe do nome deverbal que lhe serve de núcleo e do verbo leve que a constitui quanto do seu determinante.

Além disso, foi mostrado que a 'escolha' pelo verbo leve não é desmotivada, mas sistemática, e que mudanças nos elementos internos às CVLs, tais como o tipo de determinante e marca de plural, provocam alterações previsíveis na acionalidade do predicado. Em síntese, na esteira dos trabalhos de Scher (2003), Davel (2009) e Medeiros (2010), o presente artigo tentou lançar luz a outros aspectos - mais especificamente, os aspectos puramente semânticos - das CVLs e, igualmente, mostrar alguma sistematicidade com relação ao emprego dos determinantes e do morfema de plural nessas construções.

\section{Referências}

BASÍLIO, Margarida. Construções morfológicas e construções lexicais: expressões V SN com dar e fazer. In: CONGRESSO DE LETRAS, SG, 2007. Rio de Janeiro. Anais... Rio de Janeiro: UERJ, 2007.

BERTUCCI, Roberlei Alves. Uma análise semântica para verbos aspectuais no português brasileiro. 2011. 202f. Tese (Doutorado em Linguística) - Universidade de São Paulo, São Paulo.

BRINTON, Laurel J. The Aktionsart of deverbal nouns in English. In: BERTINETTO, Pier Marco; BIANCHI, Valentina; HIGGINBOTHAM, James; SQUARTINI, Mario (Eds.). Temporal reference, aspect and acionality. Tormo: Rosenberg \& Sellier. p. 27-45. 1995.

DAVEL, Alzira da Penha Costa, Medeiros. Um estudo sobre o verbo-suporte na construção dar + SN. 2009. 183 f. Dissertação (Mestrado em Estudos Linguísticos) - Universidade Federal do Espírito Santo, Vitória.

DOWTY, David R. Word meaning and Montague grammar: the semantics of verbs and times in generative semantics and in Montague's PTQ. Dordrecht: Kluwer, 1979.

KEARNS, Kate. Semantics. London: Palgrave McMillan, 2000.

LYONS, Christopher. Definiteness. Cambridge: Cambridge University, 1999.

MEDEIROS, Alessandro Boechat de. Aspecto e estrutura de evento nas nominalizações do português do Brasil: revendo o caso das nominalizações em -ada. Letras de hoje.,Curitiba, n. 81, p. 99-122, 2010.

RESENDE, Maurício Sartori. O aspecto lexical dos nomes deverbais. Via Litterae, Anápolis, v. 8, n. 1, p. 23-41. 2016. 
- Reconciliando propostas lexicalistas para a derivação regressiva. Macabéa: Revista Eletrônica do Netlli, Crato, v. 5, n. 2, p. 53-66, 2016.

. A qualidade massa/contável dos nomes deverbais. Raído, Dourados, v. 10, n. 24, p. 192-202, 2016.

ROTHSTEIN, Susan. Structuring events: a study in the semantic oflexical aspect. London: Blackwell, 2004.

SCHER, Ana Paula. Quais são as propriedades lexicais de uma construção com verbo leve?. In: MÜLLER, Ana Lúcia; NEGRÃO, Esmeralda Vailati; FOLTRAN, Maria José (Orgs.). Semântica formal. São Paulo: Contexto, 2003. p. 205-220.

. Nominalizações em -ada em construções com o verbo leve dar em português brasileiro. Letras de hoje, Porto Alegre, v. 41. n. 1. p. 29-48, 2006.

VENDLER, Zeno. Verbs and times. In: . Linguistics in philosophy. Ithaca: Cornell University, p. 97-121. 1967.

VIOTTI, Evani. A composicionalidade de sentenças com o verbo ter. In: MÜLLER, Ana Lúcia; NEGRÃO, Esmeralda Vailati; FOLTRAN, Maria José (Org.). Semântica formal. São Paulo: Contexto, 2003. p. 221-241.

WACHOWICZ, Tereza. Cristina; FOLTRAN, Maria José. Sobre a noção de aspecto. Cadernos de estudos linguísticos. Campinas. v. 2. n. 48. p. 211-232. 2006.

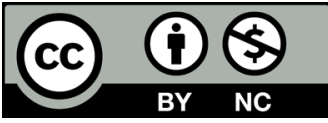

Data de submissão: 30/09/2017

Data de aceite: $15 / 06 / 2018$ 